

Published in final edited form as:

Org Lett. 2007 February 15; 9(4): 555-558. doi:10.1021/ol062751x.

\title{
Transition Structures of Diastereoselective 1,3-Dipolar Cycloadditions of Nitrile Oxides to Chiral Homoallylic Alcohols
}

\author{
Jennifer A. R. Luft, Kieche Meleson, and K. N. Houk ${ }^{*}$ \\ Department of Chemistry and Biochemistry, University of California, Los Angeles, CA 90095, USA
}

\section{Abstract}
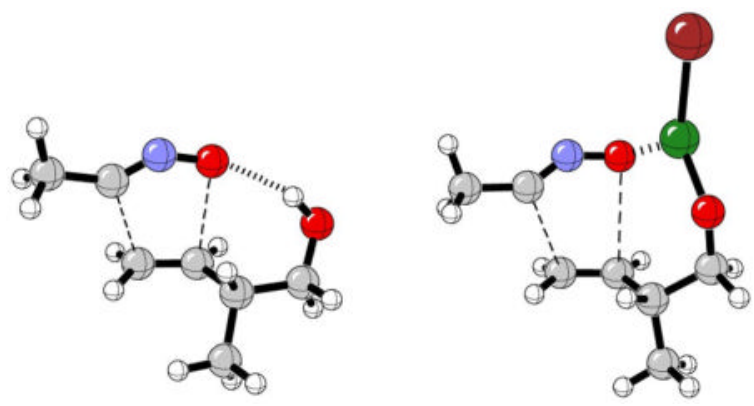

Transition structures of the 1,3-dipolar cycloaddition of substituted nitrile oxides with chiral homoallylic alcohols were explored with density functional theory (B3LYP/6-311+G(d,p)+CPCM (dichloromethane)//B3LYP/6-31+G(d)). The diastereoselectivity observed in these reactions was explained. The anti product is favored in both the thermal and magnesium-mediated reactions. Selectivity is predicted to increase in the presence of magnesium, in agreement with experimental results. The energetics of the magnesium-mediated reaction are similar to those previously found for allylic alcohols.

The 1,3-dipolar cycloadditions of chiral alkenes are widely used in organic synthesis. ${ }^{1}$ Control of diastereoselectivity in these cycloadditions is important for economical syntheses of natural products, ${ }^{2}$ particularly for the synthesis of polyketides. ${ }^{3}$ Nitrile oxide cycloadditions with allylic alcohols have been thoroughly studied, ${ }^{4}$ and theoretical calculations have given insights into the origins of their selectivities. 5

Magnesium salts have been shown to accelerate nitrile oxide cycloadditions to allylic alcohols.

6 This methodology has been useful for the synthesis of enantiopure $\beta$-hydroxy ketones and $\gamma$-amino alcohols. 7 The mechanism and energetics of magnesium-mediated cycloadditions with allylic alcohols have been investigated quantum mechanically by Fukuda et al. ${ }^{8}$

There are few literature example of dipolar cycloadditions with homoallylic alcohols, presumably due to the facile dimerization of aliphatic nitrile oxides in the absence of a reactive dipolarophile. ${ }^{9,10}$ Yields for the metal-free reaction are reasonable, but the observed regioselectivities ${ }^{9}$ and diastereoselectivities ${ }^{10}$ are low. Kanemasa et al. first published the magnesium-mediated cycloaddition of homoallylic alcohols in 1994, but reported low yields and enantioselectivities. 9 Kociolek et al. published improved yields and enantioselectivities in 2003. ${ }^{10}$ Carreira and co-workers have extended this methodology to a variety of oximes 
and monoprotected homoallylic diols to produce a range of $\Delta^{2}$-isoxazolines with reasonable yields, as shown in Scheme 1. 11

Selectivity in cycloaddition reactions has been explained using conformational analysis of transition structures. ${ }^{12}$ Transition structures prefer a staggered orientation around the forming bonds. For nitrile oxide cycloadditions, this results in three possible locations for a substituent; inside, outside, or anti relative to the forming bonds of the cycloaddition transition structure (Figure 1).

Transition structures for $\alpha$-substituted alkenes have been carefully examined. $12 \mathrm{~d}, \mathrm{e}, 13,14$ Substrates with chiral $\alpha$-alkoxy substituents prefer to orient the alkoxy group inside while large alkyl groups prefer to reside anti, $\mathbf{A}^{\prime}$. Our group has used this "inside alkoxy effect" to explain the stereoselectivities of cycloadditions of nitrile oxides with chiral allylic ethers. ${ }^{14}$ Hydroxyl groups, on the other hand, have a preference for the outside position in order to hydrogen bond with the incoming nitrile oxide oxygen; the large alkyl group continues to prefer the anti position, $\mathbf{B}^{\prime}{ }^{5 a, 8}$ Steric interactions from $Z$ alkenes have been found to alter the conformational preference of electronegative substituents. $12 \mathrm{~d}$

By analogy, the transition structures for nitrile oxide cycloadditions to homoallylic alcohols should prefer conformations such as $\mathbf{C}^{\prime}$. In this conformer, the hydroxymethyl group resides outside in order to hydrogen bond with the incoming nitrile oxide oxygen, and the methyl group resides anti. The addition of a Grignard reagent has been proposed to increase the preference for this conformer, as the magnesium will strongly coordinate to both oxygens. $7-9$

Conformational analyses of reagents, products and transition structures were computed with B3LYP/6-311+G(d,p)//B3LYP/6-31+G(d). Gas phase energetics and energetics incorporating the CPCM solvation model ${ }^{15}$ are reported. All calculations were performed using Gaussian 03. ${ }^{16}$ Computational details and references are given in supporting information. Density functional theory has been shown to be an effective method for modeling dipolar cycloadditions. $11 \mathrm{e}-\mathrm{g}, 12 \mathrm{f}-\mathrm{h}, 17$ Previous computational work on the magnesium-mediated 1,3dipolar cycloaddition of nitrile oxides with allylic alcohols implemented the MP4(SDTQ)/ 6-31G*//RHF/6-31G* and RHF/6-31G*//RHF/6-31G* levels of theory. ${ }^{8}$

There are six possible transition structures that can be formed with three staggered rotamers and involving attack on the two pro-chiral faces of the alkene. Without magnesium salts present, the hydroxymethyl group prefers to reside outside, Table 1. The outside orientation allows the hydroxymethyl group to hydrogen bond with the incoming nitrile oxide oxygen. Figure 2 shows the most stable conformers of the six transition structures of $\mathbf{6}$. With the hydroxymethyl group outside, the alkyl group prefers to reside anti by $1 \mathrm{kcal} / \mathrm{mol}$ for steric reasons $\left(\mathbf{6}_{\text {outside,anti }}\right.$ versus $6_{\text {outside,outside). }}$.

Transition structures $\boldsymbol{6}_{\text {outside,inside }}, \mathbf{6}_{\text {anti,inside }}, \boldsymbol{6}_{\text {anti,outside, and }} \mathbf{6}_{\text {inside,anti }}$ are essentially equal in energy when solvation effects are taken into account. The two transition structures that orient the hydroxyl group outside and enable hydrogen bonding, $\mathbf{6}_{\text {outside,anti }}$ and $\mathbf{6}_{\text {outside,inside, are }}$ significantly lower than the other transition structures in the gas phase calculations. Rotamer


is the least stable transition structure.

Selectivities for the thermal reaction were calculated using a Boltzmann average based on the computed relative energies from the solvation single point calculations. The thermal reaction is predicted to favor the anti diastereomeric product over the syn diastereomer by a ratio of 1.7:1. Experimentally, little selectivity is observed. Our calculations overestimate the selectivity of the thermal reaction. The conformational preference for transition structure 
$\mathbf{6}_{\text {outside,anti }}$ is similar in magnitude and direction to the conformational preference of allylic alcohols. $^{8}$

Transition structures for the magnesium-mediated case show similar conformational preferences, Table 2 . The Grignard reagent deprotonates the homoallylic alcohol and produces a magnesium complex 9. Energies in Table 2 are given relative to $\mathbf{4}$ and $\mathbf{9}$. Figure 3 contains the most stable conformers of the six possible transition structures for the magnesium-mediated process.

The magnesium ether shows a strong preference for chelation (10 $\mathbf{1 0}_{\text {outside,anti }}$ and $\mathbf{1 0}_{\text {outside,inside }}$ ). This is similar to the trend exhibited by hydroxymethyl, but with the magnesium alkoxide, the preference for the oxygen subsituent to reside outside has increased to $3 \mathrm{kcal} / \mathrm{mol}$. In the gas phase calculations, the preference for magnesium alkoxide outside is very large but inclusion of solvation stabilizes the bisligated magnesium oriented anti or inside.

With the magnesium ether outside, the alkyl group prefers to reside anti by $3.4 \mathrm{kcal} / \mathrm{mol}$ (10 $\left.\mathbf{1 0}_{\text {outside,anti }}\right)$, which is a larger preference than that observed in the thermal reaction ( $\mathbf{6}_{\text {outside,anti }}$ and $\mathbf{6}_{\text {outside,inside, where }} \mathbf{6}_{\text {outside,anti }}$ is preferred by $1.0 \mathrm{kcal} / \mathrm{mol}$ ). Gas phase energetics suggest no preference for methyl anti versus methyl inside. Conformers with magnesium ether either inside or anti are less stable by 7 to $8 \mathrm{kcal} / \mathrm{mol}$.

In both $\mathbf{1 0}$ outside conformers, the magnesium ether is stabilized by coordination with the incoming nitrile oxide oxygen. This interaction withdraws electron density from the dipolar cycloaddition transition structure. Since these transition structures are more electron-deficient, there is a greater preference for methyl anti to stabilize the transition structure through hyperconjugation.

This preference is not observed in gas phase calculations due to electrostatic interactions.

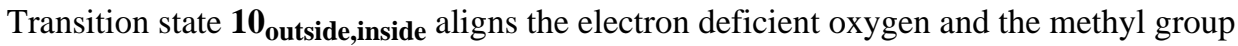
gauche, enabling a stabilizing electrostatic interaction. This interaction is minimized when solvation interactions are taken into consideration.

Diastereoselectivities were predicted using a Boltzmann average based on the calculated potential energies from the solvation single point calculations. The magnesium-mediated reaction is predicted to favor the anti product over syn by over 99:1. Carreira and coworkers report diastereoselectivites between 4:1 and 13:1. Our calculations overestimate the selectivity of the magnesium-mediated process, most likely due to the absence of explicit solvation of the magnesium in these calculations.

Diastereoselectivity of the dipolar cycloadditions of nitrile oxide to homoallylic alcohols is increased by the addition of Grignard reagents. The anti product is favored kinetically and thermodynamically, in both cases. The most stable transition structures prefer to orient the hydroxymethyl or the magnesium ether outside to maximize stabilizing interactions with the incoming nitrile oxide oxygen. The alkyl group prefers to reside anti, which minimizes steric effects and enables the $\mathrm{C}-\mathrm{C} \sigma$ bond to hyperconjugate with the $\pi^{*}$ of the alkene.

\section{Supplementary Material}

Refer to Web version on PubMed Central for supplementary material. 


\section{Acknowledgements}

We are grateful to the National Institute of General Medical Sciences, National Institutes of Health (GM 36700 to K.N.H.) for financial support. We also thank the NSF-PACI and UCLA-ATS for computing resources.

\section{References}

1. (a) Gothelf KV, Jorgensen KA. Chem Rev 1998;98:863-909. [PubMed: 11848917] (b) Huang KSL, Lee EH, Olmstead MM, Kurth MJ. J Org Chem 2000;65:499-503. [PubMed: 10813963] (c) Mishra RC, Tewari N, Verma SS, Tripathi RP, Kumar M, Shukla PK. J Carbohydr Chem 2004;23:353-374. (d) Sengupta J, Mukhopadhyay R, Bhattacharjya A, Bhadbhade MM, Bhosekar GV. J Org Chem 2005;70:8579-8582. [PubMed: 16209613] (e) Savage GP, Wernert GT. Aust J Chem 2005;58:877881.

2. (a) Pal A, Bhattacharjee A, Bhattacharjya A. Synthesis 1999;9:1569-1572. (b) Nivlet A, Dechoux L, Martel JP, Proess G, Mannes D, Alcaraz L, Harnett JJ, Le Gall T, Mioskowski C. Eur J Org Chem 1999;12:3241-3249. (c) Aungst RA Jr, Chan C, Funk RL. Org Lett 2001;3:2611-2613. [PubMed: 11483073] (d) Kim D, Lee J, Shim PJ, Lim JI, Jo H, Kim S. J Org Chem 2002;67:764-771. [PubMed: 11856018]

3. (a) Moriya O, Takenaka H, Iyoda M, Urata Y, Endo T. J Chem Soc Perkin Trans 1 1994:413-417. (b) Fader LD, Carreira EM. Org Lett 2004;6:2485-2488. [PubMed: 15228310] (c) Ghorai S, Mukhopadhyay R, Kundu AP, Bhattacharjya A. Tetrahedron 2005;61:2999-3012. (d) Kumar V, Kaushik MP. Tetrahedron Lett 2006;47:1457-1460.

4. (a) Merino P, Tejero T, Laguna M, Cerrada E, Moreno A, Lopez JA. Org Biomol Chem 2003;1:23362342. [PubMed: 12945706] (b) Chiacchio U, Rescifina A, Saita MG, Iannazzo D, Romeo G, Mates JA, Tejero T, Merino P. J Org Chem 2005;70:8991-9001. [PubMed: 16238338]

5. (a) Houk KN, Moses SR, Wu YD, Rondan NG, Jäger V, Schohe R, Fronczek FR. J Am Chem Soc 1984;106:3380-3882. (b) Houk KN, Duh HY, Wu YD, Moses SR. J Am Chem Soc 1986;108:27542755. (c) Annunziata R, Benaglia M, Cinquinu M, Cozzi F, Raimondi L. J Org Chem 1995;60:46974706.

6. (a) Kanemasa S, Nishiuchi M, Wada E. Tetrahedron Lett 1992;33:1357-1360. (b) Kanemasa S, Nishiuchi M, Kamimura A, Hori K. J Am Chem Soc 1994;116:2324-2339. (c) Kanemasa S, Tsuruoka T. Chem Lett 1995:49-50. (d) Kanemasa S, Okuda K, Yamamoto H, Kaga S. Tetrahedron Lett 1997;38:4095-4098. (e) Kanemasa S. Synlett 2002;9:1371-1387. (f) Kociolek MG, Hongfa C. Tetrahedron Lett 2003;44:1811-1813.

7. (a) Bode JW, Carreira EM. J Am Chem Soc 2001;123:3611-3612. [PubMed: 11472140] (b) Kim HC, Woo SW, Seo MJ, Jeon MJ, Jeon DJ, No Z, Kim HR. Synlett 2002:1691-1693. (c) Seo MJ, Son BS, Son BG, Song BJ, Lee SD, Kim JY, Kim HD, No Z, Kim HR. Bull Korean Chem Soc 2005;26:15971599.

8. Fukuda S, Kamimura A, Kanemasa S, Hori K. Tetrahedron 2000;56:1637-1647.

9. Kanemasa S, Nishiuchi M, Kamimura A, Hori K. J Am Chem Soc 1994;116:2324-2339.

10. Kociolek MG, Hongfa C. Tetrahedron Lett 2003;44:1811-1813.

11. Lohse-Fraefel N, Carreira EM. Org Lett 2005;7:2011-2014. [PubMed: 15876042]

12. (a) Brown FK, Raimondi L, Wu YD, Houk KN. Tetrahedron Lett 1992;33:4405-4408.Fallis, AG.; Lu, YF. Advances in Cycloaddition. Curran, DP., editor. 1. JAI Press Inc; Greenwich, CT: 1993. p. 1-66. (c) Kim HR, Kim KM, Kim JN, Ryu EK. Synth Commun 1994;24:1107-1116. (d) Silvero G, Lucero MJ, Winterfeldt E, Houk KN. Tetrahedron 1998;54:7293-7300. (e) Corsaro A, Pistarà V, Rescifina A, Piperno A, Chiacchio MA, Romeo G. Tetrahedron 2004;60:6443-6451. (f) Ponti A, Molteni G. J Org Chem 2001;66:5252-5255. [PubMed: 11463282] (g) Ponti A, Molteni G. New J Chem 2002;26:1346-1351.

13. (a) Jäger V, Schohe R, Paulus EF. Tetrahedron Lett 1983;24:5501-5504. (b) Kozikowski AP, Ghosh AK. J Org Chem 1984;49:2762-2772. (c) Jäger V, Schröter D. Synthesis 1990:556-560. (d) Armstrong SK, Collington EW, Warren S. J Chem Soc, Perkin Trans 1 1994:515-519. (e) Busqué F, de March P, Figueredo M, Font J, Monsalvatje M, Virgili A, Álvarez-Larena Á, Piniella JF. J Org Chem 1996;61:8578-8585. (f) Haller J, Strassner T, Houk KN. J Am Chem Soc 1997;119:80318034. (g) Grée D, Vallerie L, Grée R, Toupet L, Washington I, Pelicier JP, Villacampa M, Pérez JM,

Org Lett. Author manuscript; available in PMC 2008 September 11. 
Houk KN. J Org Chem 2001;66:2374-2381. [PubMed: 11281778] (h) Prakesch M, Grée D, Grée R, Carter J, Washington I, Houk KN. Chem Eur J 2003;9:5664-5672.

14. (a) Houk KN, Moses SR, Wu YD, Rondan NG, Jäger V, Schohe R, Fronczek FR. J Am Chem Soc 1984;106:3880-3882. (b) Raimondi L, Wu YD, Brown FK, Houk KN. Tetrahedron Lett 1992;33:4409-4412.

15. (a) Barone V, Cossi M. J Phys Chem A 1998;102:1995-2001. (b) Barone B, Cossi M, Tomasi J. J Comput Chem 1998;19:404-417.

16. Frisch, MJ.; Trucks, GW.; Schlegel, HB.; Scuseria, GE.; Robb, MA.; Cheeseman, JR.; Montgomery, JA., Jr; Vreven, T.; Kudin, KN.; Burant, JC.; Millam, JM.; Iyengar, SS.; Tomasi, J.; Barone, V.; Mennucci, B.; Cossi, M.; Scalmani, G.; Rega, N.; Petersson, GA.; Nakatsuji, H.; Hada, M.; Ehara, M.; Toyota, K.; Fukuda, R.; Hasegawa, J.; Ishida, M.; Nakajima, T.; Honda, Y.; Kitao, O.; Nakai, H.; Klene, M.; Li, X.; Knox, JE.; Hratchian, HP.; Cross, JB.; Adamo, C.; Jaramillo, J.; Gomperts, R.; Stratmann, RE.; Yazyev, O.; Austin, AJ.; Cammi, R.; Pomelli, C.; Ochterski, JW.; Ayala, PY.; Morokuma, K.; Voth, GA.; Salvador, P.; Dannenberg, JJ.; Zakrzewski, VG.; Dapprich, S.; Daniels, AD.; Strain, MC.; Farkas, O.; Malick, DK.; Rabuck, AD.; Raghavachari, K.; Foresman, JB.; Ortiz, JV.; Cui, Q.; Baboul, AG.; Clifford, S.; Cioslowski, J.; Stefanov, BB.; Liu, G.; Liashenko, A.; Piskorz, P.; Komaromi, I.; Martin, RL.; Fox, DJ.; Keith, T.; Al-Laham, MA.; Peng, CY.; Nanayakkara, A.; Challacombe, M.; Gill, PMW.; Johnson, B.; Chen, W.; Wong, MW.; Gonzalez, C.; Pople, JA. Gaussian. 03. Gaussian Inc; Pittsburgh, PA: 2003. Revision B.05

17. (a) Chandra AK, Nguyen MT. J Phys Chem A 1998;102:6181-6185. (b) Cossío FP, Morao I, Jiao H, Schleyer P, von R. J Am Chem Soc 1999;121:6737-6746. (c) Herrera R, Nagarajan A, Morales MA, Méndez F, Jiménez-Vásquez HA, Zepeda LG, Tamariz J. J Org Chem 2001;66:1252-1253. [PubMed: 11312955] (d) Lu X, Xu X, Wang N, Zhang Q. J Org Chem 2002;67:515-520. [PubMed: 11798325] (e) Yu ZX, Houk KN. J Am Chem Soc 2003;125:13825-13830. [PubMed: 14599222] (f) Himo F, Lovell T, Hilgraf R, Rostovtsev VV, Noodleman L, Sharpless BM, Fokin VV. J Am Chem Soc 2005;127:210-216. [PubMed: 15631470] (g) Alvarez A, Estael O, Yamila V, Margarita S, Miquel S, Nazario M. J Org Chem 2005;7:5289-5291. (h) Castillo R, Andrés J, Domingo LR. Eur J Org Chem 2005:4705-4709. (i) Ess D, Houk KN. J Phys Chem A 2005;109:9542-9553. [PubMed: 16866406] (j) Milet A, Gimbert Y, Greene AE. J Comput Chem 2006;27:157-162. [PubMed: 16312017] (k) Ponti A, Molteni G. Chem Eur J 2006;12:1156-1161.

Org Lett. Author manuscript; available in PMC 2008 September 11. 

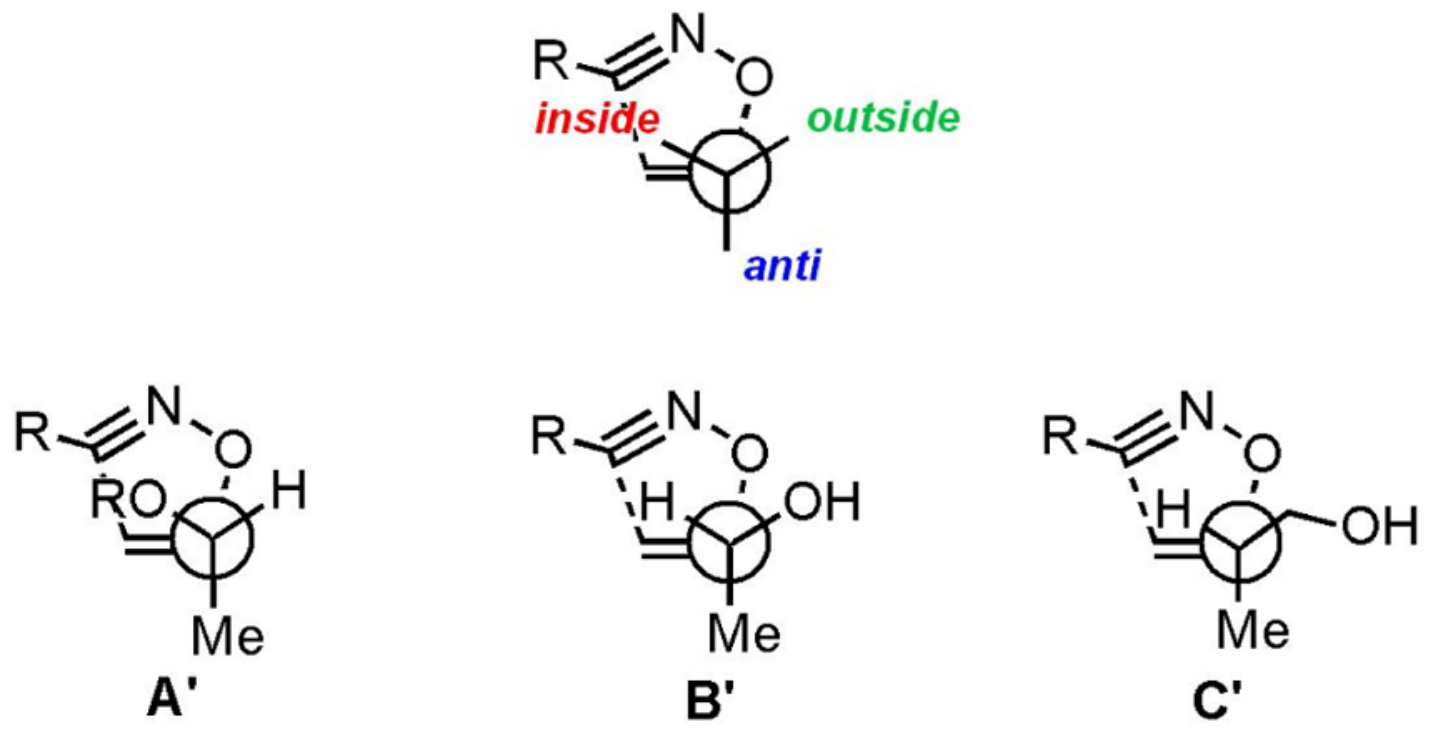

Figure 1.

Model transition structures with alkoxy, $\mathbf{A}^{\prime}$, hydroxy, $\mathbf{B}^{\prime}$, and hydroxymethyl, $\mathbf{C}^{\prime}$, substituents. 


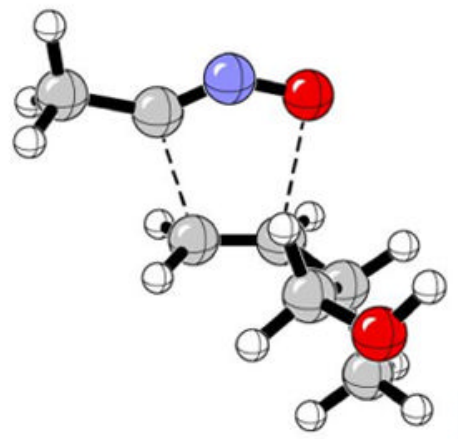

\section{$6_{\text {inside,anti }}$ $E_{\text {rel }}=1.6$}
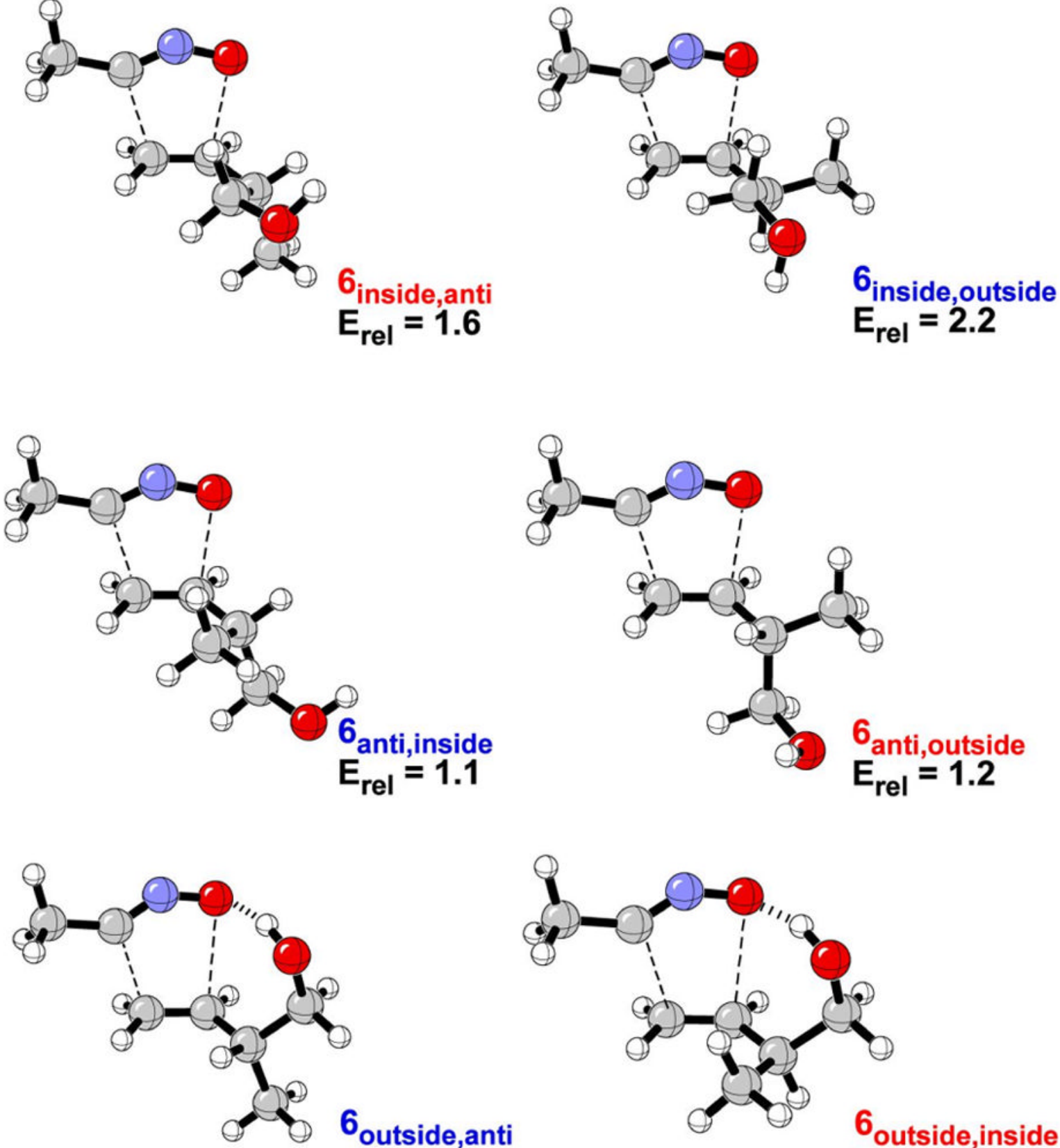

6 outside,anti $\mathrm{E}_{\text {rel }}=\mathbf{0 . 0}$

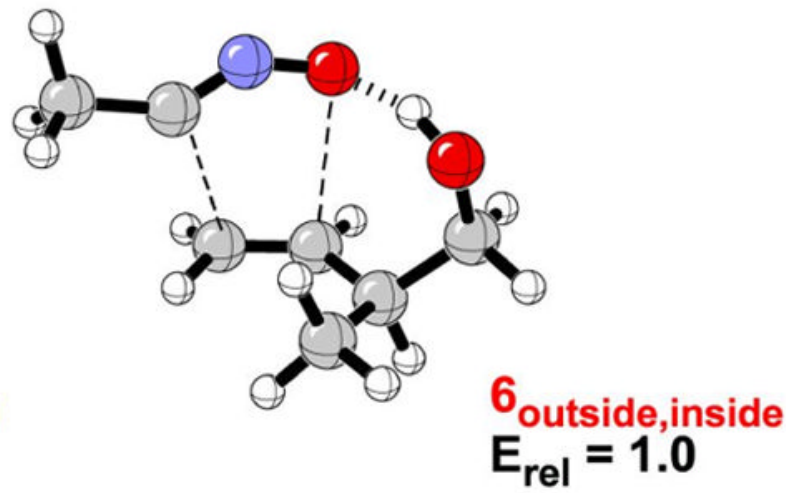

Figure 2.

B3LYP/6-311+G(d,p) + CPCM (dichloromethane)//B3LYP/6-31+G(d) transition structures for dipolar cycloaddition of $\mathbf{4}$ to $\mathbf{5}$. Energies are in $\mathrm{kcal} / \mathrm{mol}$. 

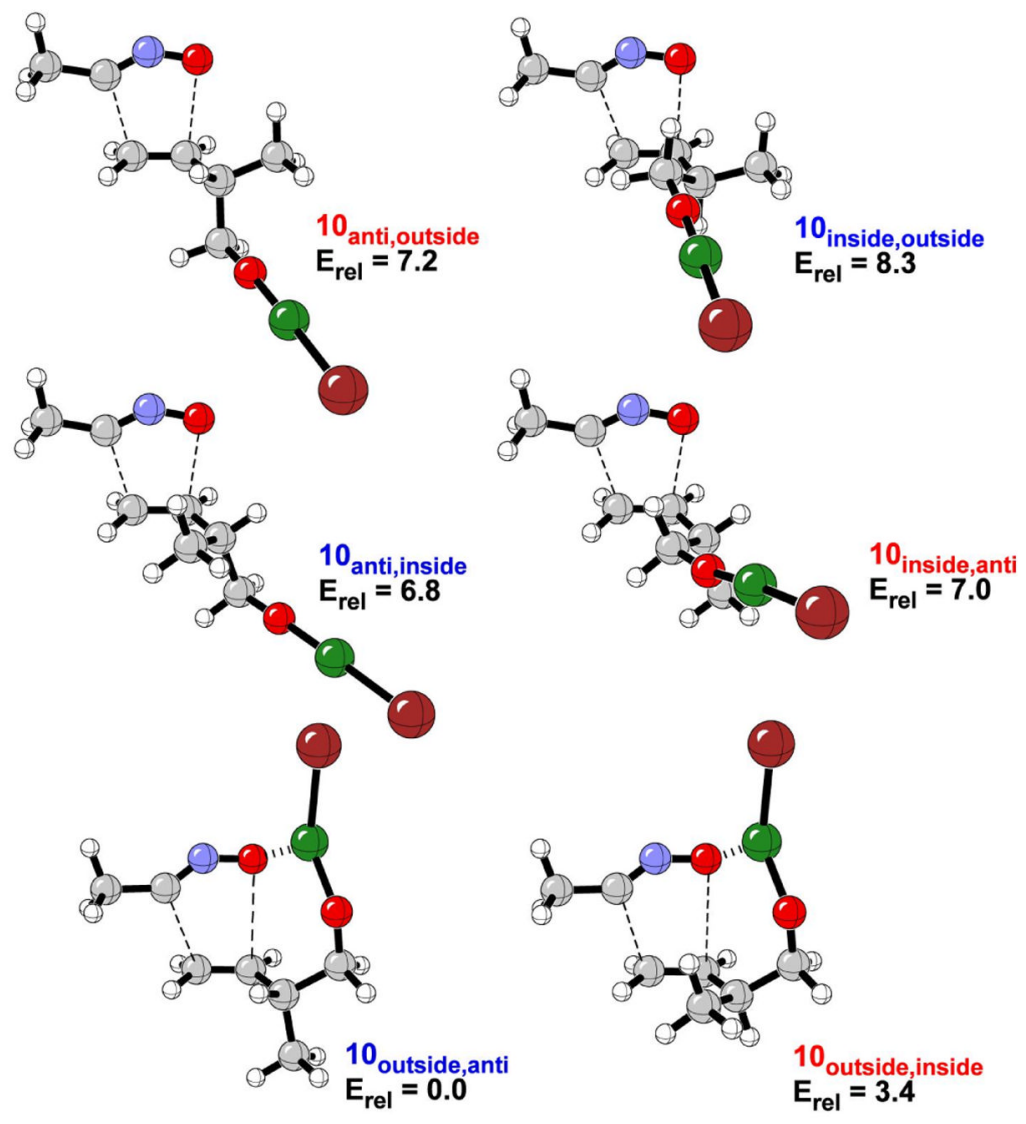

Figure 3.

B3LYP/6-311+G(d,p) + CPCM (dichloromethane)//B3LYP/6-31+G(d) transition structures for dipolar cycloaddition of $\mathbf{4}$ to 5 in the presence of $\mathrm{MeMgBr}(\mathbf{8})$. Energies are in $\mathrm{kcal} / \mathrm{mol}$. 
<smiles>[R]/C=N\O</smiles>
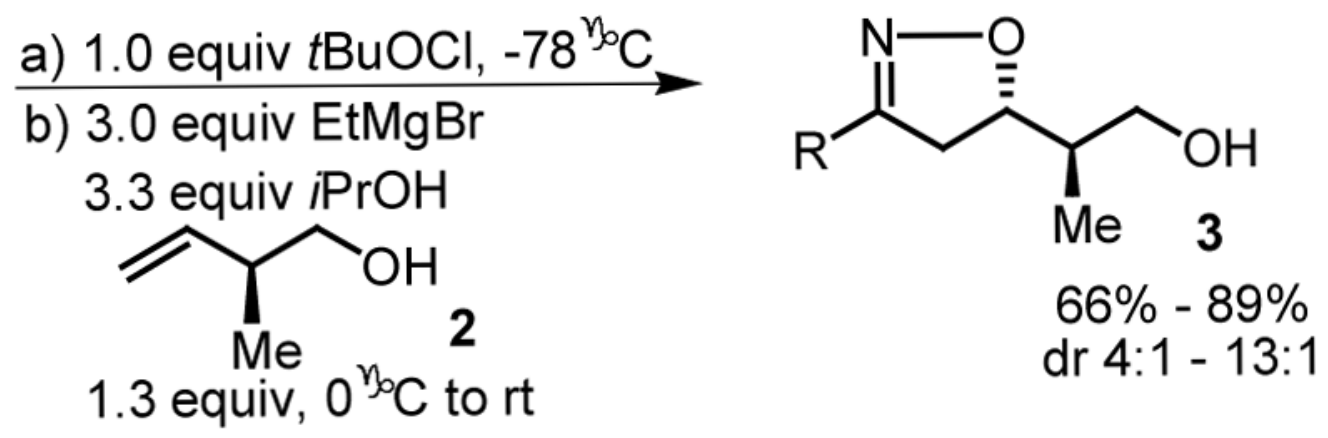

Scheme 1.

Diastereoselective Dipolar Cycloaddition of Nitrile Oxides to Homoallylic Alcohols 



Org Lett. Author manuscript; available in PMC 2008 September 11. 

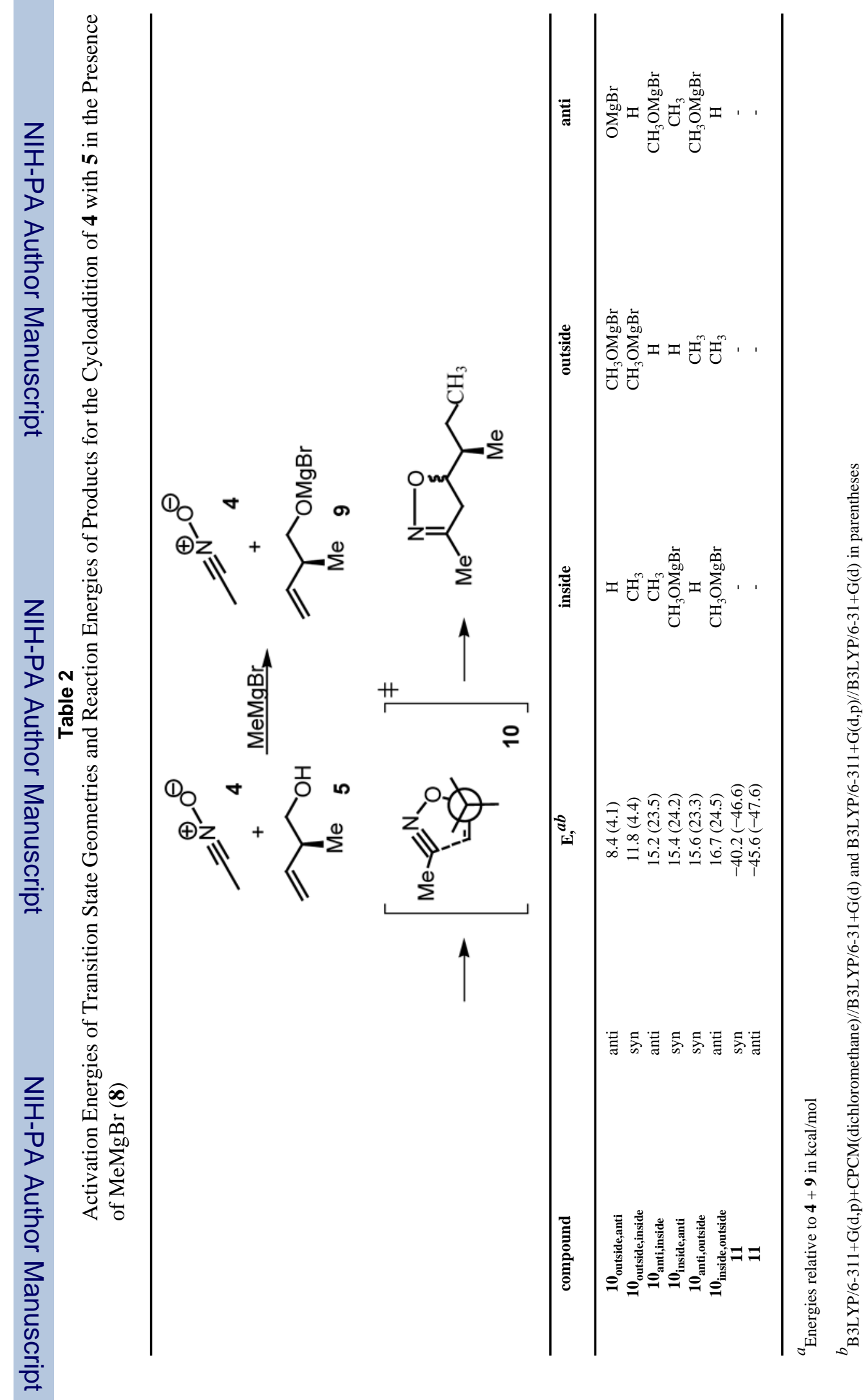